\title{
INTERPRETAÇÃO DO USO, DO MOBILIÁRIO E DA ARBORIZAÇÃO DA PRAÇA SETE DE SETEMBRO, RIBEIRÃO PRETO, SP
}

\author{
Renata Gimenes ${ }^{1}$; Gustavo da Nobrega Romani²; Gisele Sales Batista ${ }^{1}$; Kathia \\ Fernandes Lopes Pivetta ${ }^{3}$
}

(recebido em 24.05.2010 e aceito para publicação em 15.09.2011)

\section{RESUMO}

As praças são espaços públicos urbanos livres de edificações com a função de promover convivência sadia à população, oferecendo recreação e bem estar num ambiente agradável. Muitas das praças foram implantadas há muitos anos; algumas passaram por reformas, no entanto, é importante que se faça uma análise periódica a fim de adequar às necessidades dos usuários. Desta forma este trabalho teve como objetivo analisar quali-quantitativamente o mobiliário, a arborização e avaliar as funções da Praça Sete de Setembro, uma das mais freqüentadas da região central do município de Ribeirão Preto, SP. Foi feita uma pesquisa de opinião na praça, em dias da semana e horários diferentes, por meio de 100 questionários com perguntas diretas aos entrevistados. Realizado um levantamento e analisado o mobiliário da praça e as espécies arbóreas. Concluiu-se que a Praça Sete de Setembro é usada para reunir e promover lazer a diferentes grupos de pessoas, preferencialmente do sexo feminino, de 21 a 40 anos, para descanso e passeio com as crianças; o espaço oferece aos seus usuários mobiliário adequado e em bom estado de conservação; apresenta grande diversidade de espécies arbóreas (85 espécies em 280 exemplares).

Palavras-chave: Análise quali-quantitativa; Espaço público; Espécies arbóreas.

\footnotetext{
${ }^{1}$ Doutorandas do Programa de Produção Vegetal, Universidade Estadual Paulista, UNESP/ FCAVJaboticabal, Departamento de Horticultura, Jaboticabal, SP, regimenes@ig.com.br; gismel@gmail.com

2 Mestrando do Programa de Produção Vegetal, Universidade Estadual Paulista, UNESP/FCAVJaboticabal, Departamento de Horticultura, Jaboticabal, SP, gustavonromani@hotmail.com

${ }_{3}$ Professora Doutora, Universidade Estadual Paulista, UNESP/FCAV-Jaboticabal, Departamento de Horticultura, Jaboticabal, SP, kathia@fcav.unesp.br
} 


\title{
INTERPRETATION OF USE, FURNITURE AND URBAN FOREST OF SETE DE SETEMBRO SQUARE, RIBEIRÃO PRETO, SP
}

\begin{abstract}
Squares are urban public places without buildings that have the function to promote a healthy living of population, offering recreation and welfare in a pleasant environment. Many squares have been implemented over many years ago, some have gone through renovations, however, it is important to make a periodic assessment in order to adapt them to user needs. Thus this study aimed to do a quali-quantitative analysis of square furniture, trees and assess the functions of Sete de Setembro Square, which is one of the most frequented squares in central area of Ribeirão Preto, Brazil. It was applied an opinion poll in different day times and week days, to 100 visitors, through a questionnaire with direct questions. Also it was made a survey and analysis of furniture and tree species existing in the place. It was concluded that Sete de Setembro Square is visited by different people groups in order to have leisure, especially by women, people from 21 to 40 years old, to rest and let kids walk; offering to visitors suitable furniture in good condition, presents a large diversity of tree species (85 species in 280 exemplars).
\end{abstract}

Keywords: Quali-quantitative analysis; Public place; Tree species.

\section{INTRODUÇÃO}

A Praça Sete de Setembro, que antes foi chamada de Aureliano de Gusmão, é de grande importância para a cidade, pois além de ser uma praça bastante antiga, é tida como um exemplo para os ribeirão-pretanos, onde semanalmente acontecem feiras de artesanato, exposições de quadros e esculturas, e uma vez por mês apresentações musicais. A praça possui uma área total de $16.619,41 \mathrm{~m}^{2}$, sendo bastante arborizada, promovendo uma qualidade de vida melhor para a população.

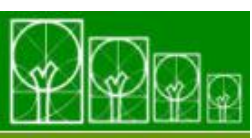

S $\cdot \mathbf{B} \cdot \mathbf{A} \cdot \mathbf{U}$ Soc. Bras. de Arborização Urbana

REVSBAU, Piracicaba - SP, v.6, n.3, p.22-42, 2011 
As praças são espaços livres, públicos, urbanos, de manifestação social, cultural e política, destinados ao lazer e ao convívio da população. É um elemento urbano muito antigo, pois já nas cidades gregas do século VI a.C. ocorriam manifestações políticas nestes locais. A história das praças está diretamente ligada à evolução histórica do paisagismo e dos costumes da época (PIVETTA et al., 2008).

As praças são locais fundamentais para a vida urbana e o seu modo de tratamento e uso indicam o nível de civilidade de seus usuários e o exercício dos direitos e deveres de cidadania nela vivenciados. É pelo uso que as pessoas fazem de uma praça um espaço importante para o seu dia-a-dia e convívio social (SOUZA, 2005).

Para De Angelis et al. (2005), a imagem que se tem das praças brasileiras é de um espaço pobre e abandonado. Muitas vezes são utilizadas como estacionamentos ou cercadas por grades, desta forma rouba-se da população um espaço nobre de convivência e lazer.

O crescimento rápido do município de Ribeirão Preto, atualmente com uma população de 563.107 habitantes (IBGE, 2010), é muito preocupante, o aumento dos condomínios fechados desmatando o pouco que resta das matas e as inundações que a cidade sofre anualmente traz sérios problemas à cidade.

O estudo das praças é importante para que se possa adequar às necessidades dos usuários, pois muitas são antigas e nem passaram por reformas, ou foram feitas interferências com pouco ou nenhum critério técnico.

Muitos estudos de análise de praças brasileiras vêm sendo feitos como os realizados por Pegolo e Demattê (2002), De Angelis et al. (2005), Silva et al. (2007), Melo e Romanini (2008), Silva et al. (2008), Borella (2009). Estes estudos trazem grande benefício à população local e levantam questões de ordem geral que possibilita o avanço da discussão, consequentemente, da readequação das praças.

Desta forma este trabalho teve como objetivo analisar quali-quantitativamente 0 mobiliário, a arborização e avaliar as funções da Praça Sete de Setembro, uma das mais freqüentadas da região central do município de Ribeirão Preto, SP.

\section{MATERIAIS E MÉTODOS}

O trabalho foi realizado na Praça Sete de Setembro, localizada na região central do município de Ribeirão Preto, SP, entre as ruas Sete de Setembro, Floriano Peixoto, Lafaiete

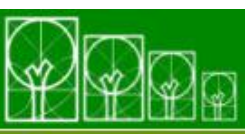

S $\cdot \mathbf{B} \cdot \mathbf{A} \cdot \mathbf{U}$ Soc. Bras. de Arborização Urbana 
e Florêncio de Abreu, no período de Agosto de 2009 à Janeiro de 2010, sendo dividido em três etapas:

\section{Análise quali-quantitativa da arborização}

Foi realizado um levantamento das espécies vegetais arbóreas encontradas na praça. A identificação das espécies foi feita a campo e a classificação com base na literatura (BRUMMITT; POWELL, 1992; LORENZI, 1992; APG II, 2003; SOUZA; LORENZI, 2008).

\section{Levantamento quali-quantitativo do mobiliário}

O levantamento foi baseado na metodologia proposta por De Angelis et al. (2004). Para a análise quantitativa do mobiliário foram assinaladas a presença ou ausência do mesmo na praça e, sempre que possível, determinou-se o material com o qual foram confeccionados.

Para a análise qualitativa do mobiliário utilizou-se a tabela 1 que avaliou o estado de conservação da mobília existente. De acordo com a metodologia proposta, foram utilizados os seguintes conceitos: péssimo (nota de 0 - 0,5), mobília sem conservação, necessitando de substituição; ruim (nota de 0,5 - 1,5), mobília sem conservação, necessitando de reforma; regular (nota 1,5 - 2,5), mobília que necessita de poucos reparos; bom (nota 2,5 - 3,5), mobília conservada, mas insuficiente para o número de usuários e ótimo (nota 3,5 - 4,0), mobília apropriada ao uso.

Tabela 1. Avaliação da infraestrutura encontrada na Praça Sete de Setembro, Ribeirão Preto, SP, 2010

Table 1. Assessment of infrastructure found in Sete de Setembro Square, Ribeirão Preto, SP, 2010

\begin{tabular}{l|l|l}
\hline ESTRUTURAS AVALIADAS & NOTA & AUSÊNCIA \\
\hline 01. Bancos & & \\
02. lluminação alta & & \\
03. lluminação baixa & & \\
04. Lixeiras & & \\
05. Sanitários & & \\
06. Telefone público & & \\
07. Bebedouros &
\end{tabular}

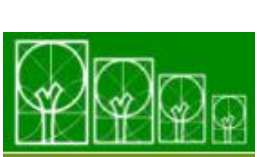


08. Piso

09. Traçado dos caminhos

10. Palco/coreto

11. Pergolado

12. Monumento

13. Espelho d'água/chafariz

14. Estacionamento

15. Ponto de ônibus

16. Ponto de táxi

17. Quadra esportiva

18. Equipamentos para exercícios físicos

19. Estrutura para terceira idade

20. Parque infantil

21. Banca de revista

22. Quiosque para alimentação e/ou similar

23. Vegetação

24. Paisagismo

25. Localização

26. Conservação/Limpeza

27. Segurança

28. Conforto ambiental

Fonte: adaptado de De Angelis et al., 2004.

\section{Pesquisa de opinião}

Realizou -se uma pesquisa de opinião com 100 pessoas presentes na praça, em dias da semana e horários diferentes, para conhecer a importância e a utilização do local pelos freqüentadores. Utilizou-se um questionário adaptado ao proposto pelo método de De Angelis e Angelis Neto (2000). Neste questionário foi levado em consideração a idade; sexo; nível escolar; atividade ocupacional; período, dia da semana, freqüência, tempo de permanência e motivo de ir à praça; o que aprecia e menos aprecia no local em questão; o que necessita melhorar; opinião das praças da cidade em que mora; mudança na infraestrutura no decorrer do tempo; conhecimento do nome e da história da praça.

\section{RESULTADOS E DISCUSSÃO}

\section{Análise quali-quantitativa da arborização}

Foram catalogados 280 indivíduos, sendo 85 espécies distribuídas em 65 gêneros e 27 famílias. As famílias de maior representação foram: Arecaceae $(21,4 \%)$, Leguminosae- 
Caesalpinioideae (18,2\%) e Bignoniaceae (11,8\%), conforme tabela 1. Os gêneros de maior representação são: Caesalpinia (27), Tabebuia (25), Phoenix (15), Cariniana (15), Eugenia (13) e Syagrus (13).

As espécies que se destacam com maior número de indivíduos são: Caesalpinia peltophoroides Benth. (18), Aspidosperma polyneuron Mull. Arg. (13), Tabebuia roseo-alba (Ridley) Sandwith (13), Syagrus romanzoffiana (Cham.) Glassman (12) e Phoenix roebelenii O’ Brien (11). As espécies restantes estão em menor número de exemplares e a maioria são espécies arbóreas nativas do Brasil (tabela 2).

Tabela 2. Levantamento das espécies arbóreas da Praça Sete de Setembro em Ribeirão

$$
\text { Preto, SP }
$$

Table 2. Survey of tree species in Sete de Setembro Square in City of Ribeirão Preto, SP

\begin{tabular}{|c|c|c|c|c|}
\hline NOME CÍENTÍFICO & NOME COMUM & FAMÍLIA & NI & N/E \\
\hline Caesalpinia peltophoroides Benth. & Sibipiruna & Caesalpinioideae & 18 & $\mathrm{~N}$ \\
\hline Aspidosperma polyneuron Mull. Arg. & Peroba-rosa & Apocynaceae & 13 & $\mathrm{~N}$ \\
\hline Tabebuia roseo-alba (Ridley) Sandwith & Ipê-branco & Bignoniaceae & 13 & $\mathrm{~N}$ \\
\hline Syagrus romanzoffiana (Cham.) Glassman & Palmeira-jerivá & Arecaceae & 12 & $\mathrm{~N}$ \\
\hline Phoenix roebelenii O'Brien & Palmeira-phoenix & Arecaceae & 11 & $E$ \\
\hline Tabebuia impetiginosa (Mart. ex DC.) Standl. & Ipê-roxo & Bignoniaceae & 9 & $\mathrm{~N}$ \\
\hline Hymenaea courbaril L. & Jatobá & Caesalpinioideae & 8 & $\mathrm{~N}$ \\
\hline Eugenia jambolana Lam. & Jambolão & Myrtaceae & 7 & $\mathrm{~N}$ \\
\hline Machaerium villosum Vogel & Jacarandá-paulista & Papilionoideae & 7 & $\mathrm{~N}$ \\
\hline Miroxylon peruiferum L.f. & Cabreúva & Caesalpinioideae & 7 & $\mathrm{~N}$ \\
\hline Brunfelsia uniflora D. Don & Manacá & Solanaceae & 6 & $\mathrm{~N}$ \\
\hline Caesalpinia echinata Lam. & Pau-brasil & Caesalpinioideae & 6 & $\mathrm{~N}$ \\
\hline Eugenia uniflora L. & Pitanga & Myrtaceae & 6 & $\mathrm{~N}$ \\
\hline Lecythis pisonis Cambess. & Sapucaia & Lecythidaceae & 6 & $\mathrm{~N}$ \\
\hline Licania tomentosa (Benth.) Fritsch. & Oiti & Chrysobalanaceae & 6 & $\mathrm{~N}$ \\
\hline Bactris gasipaes Kunth. & Pupunha & Arecaceae & 5 & $\mathrm{~N}$ \\
\hline Guarea guidonia L. Sleumer & Marinheiro & Meliaceae & 5 & $\mathrm{~N}$ \\
\hline Murraya paniculata (L.) Jack & Falsa-murta & Rutaceae & 5 & $E$ \\
\hline Rhapis excelsa (Thumberg) Henry ex. Rehder & Palmeira-ráfis & Arecaceae & 5 & $E$ \\
\hline Scheelea phalerata (Mart.) & Palmeira-chelia & Arecaceae & 5 & $\mathrm{~N}$ \\
\hline Syzygium malaccense (L.) Merr. \& LM Perry & Jambo-vermelho & Myrtaceae & 5 & $E$ \\
\hline Ficus elastica Roxb. Ex Hornem & Falsa-seringueira & Moraceae & 4 & $E$ \\
\hline Jacaranda brasiliana (Lam.) Pers. & Jacarandá-boca-sapo & Bignoniaceae & 4 & $\mathrm{~N}$ \\
\hline Tabebuia chrysotricha (Mart. ex DC.) Standl. & Ipê-amarelo & Bignoniaceae & 4 & $\mathrm{~N}$ \\
\hline Albizia hasslerii (Chod.) Burkart. & Farinha-seca & Mimosoideae & 3 & $\mathrm{~N}$ \\
\hline Archontophoenix alexandrae H. Wendl \& Drude & Real-australiana & Arecaceae & 3 & $E$ \\
\hline Caesalpinia ferrea Mart. ex Tul. & Pau-ferro & Caesalpinioideae & 3 & $\mathrm{~N}$ \\
\hline Cassia fistula L. & Chuva-de-ouro & Caesalpinioideae & 3 & $\mathrm{~N}$ \\
\hline Centrolobium microchaete (Benth.) H.C.Lima & Araribá & Papilionoideae & 3 & $\mathrm{~N}$ \\
\hline Fícus guarnitica Chod. Ex Chod. \& Vischer & Figueira-branca & Moraceae & 3 & $\mathrm{~N}$ \\
\hline Ligustrum lucidum W. T. Aiton & Alfeneiro-do-japão & Oleaceae & 3 & $E$ \\
\hline Livistona chinensis R. BR. & Palmeira-leque & Arecaceae & 3 & $\mathrm{~N}$ \\
\hline Orbignya speciosa (Mart.) Barb. Rodr. & Babaçu & Arecaceae & 3 & $\mathrm{~N}$ \\
\hline Phoenix dactylifera L. & Tamareira & Arecaceae & 3 & $\mathrm{~N}$ \\
\hline
\end{tabular}


Plumeria rubra (L.) Woodson

Spondias mombin L.

Tabebuia heptaphylla (Vell.) Toledo

Tamarindus indica L.

Anacardium occidentale L.

Annona muricata L.

Artocarpus heterophyllus Lam.

Cariniana estrellensis (Raddi) Kuntze

Ceiba boliviana Britten \& Baker $\mathrm{f}$.

Dypsis lutescens H. (Wendl.) Beentje \& J. Dransf.

Elaeis guianeensis Jacq.

Genipa americana L.

Inga uraguensis Hook. \& Arn.

Machaerium opacum Vogel

Malpighia glabra L.

Pachira aquatica Aubl.

Swietenia macrophylla King.

Thevetia peruviana (Pers.) K.Schum.

Aspidosperma cylindrocarpon Mull. Arg.

Aspidosperma pyrifolium Mart.

Averrhoa carambola L.

Bixa orelana L.

Cariniana legalis (Mart.) Kuntze

Cariniana rubra Gardner ex Miers

Cassia excelsa Schrad.

Cedrela fissilis Vell.

Copaifeira langsdorffii Desf.

Cytharexyllum myrianthum Cham.

Euterpe edulis Mart.

Ficus insípida Willd.

Holocalix balansae Micheli

Morus Alba L.

Morus nigra L.

Nectandra megapotamica (Spreng.) Mez

Oreopanax fulvum Marchal.

Parapiptadenia pterosperma (Bojer) Brenan

Phoenix reclinata Jacq.

Pilocarpus jaborandi Holmes

Psidium guajava L.

Ptychosperma macarthurii H. Wendl. ex Hook f.

Roystonea oleracea (Jacq.) Cook

Schinus terebinthifolia Raddi

Sterculia apetala (Jacq.) H.Karst.

Syagrus oleraceae (Mart.) Becc.

Syzygium jambolana DC.

Syzygium samarangense (Blume)Merr. \& LMPerry

Terminalia catappa L.

Theobroma cacao L.

Thrinax parviflora Swartz.

Thuja occidentalis L.

Trichilia hirta

$\mathrm{NI}$ = número de indivíduos; N/E = nativa/exótica

$\mathrm{NI}=$ number of individuals; $\mathrm{N} / \mathrm{E}=$ native/exotic

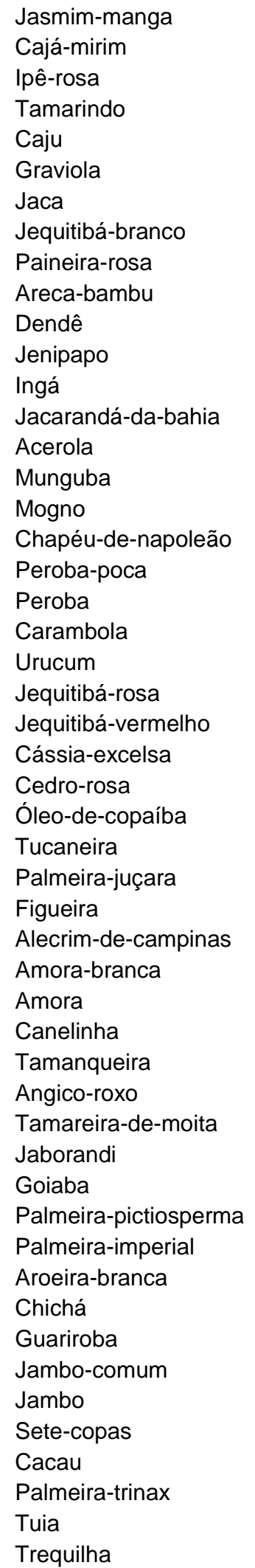

\begin{tabular}{|c|c|}
\hline Apocynaceae & 3 \\
\hline Anacardiaceae & 3 \\
\hline Bignoniaceae & 3 \\
\hline Caesalpinioideae & 3 \\
\hline Anacardiaceae & 2 \\
\hline Annonaceae & 2 \\
\hline Moraceae & 2 \\
\hline Lecythidaceae & 2 \\
\hline Bombacaceae & 2 \\
\hline Arecaceae & 2 \\
\hline Arecaceae & 2 \\
\hline Rubiaceae & 2 \\
\hline Mimosoideae & 2 \\
\hline Papilionoideae & 2 \\
\hline Malpighiaceae & 2 \\
\hline Bombacaceae & 2 \\
\hline Meliaceae & 2 \\
\hline Apocynaceae & 2 \\
\hline Apocynaceae & 1 \\
\hline Apocynaceae & 1 \\
\hline Oxalidaceae & 1 \\
\hline Bixaceae & 1 \\
\hline Lecythidaceae & 1 \\
\hline Lecythidaceae & 1 \\
\hline Caesalpinioideae & 1 \\
\hline Meliaceae & 1 \\
\hline Caesalpinioideae & 1 \\
\hline Verbenaceae & 1 \\
\hline Arecaceae & 1 \\
\hline Moraceae & 1 \\
\hline Caesalpinioideae & 1 \\
\hline Moraceae & 1 \\
\hline Moraceae & 1 \\
\hline Lauraceae & 1 \\
\hline Araliaceae & 1 \\
\hline Mimosoideae & 1 \\
\hline Arecaceae & 1 \\
\hline Rutaceae & 1 \\
\hline Myrtaceae & 1 \\
\hline Arecaceae & 1 \\
\hline Arecaceae & 1 \\
\hline Anacardiaceae & 1 \\
\hline Sterculiaceae & 1 \\
\hline Arecaceae & 1 \\
\hline Myrtaceae & 1 \\
\hline Myrtaceae & 1 \\
\hline Combretaceae & 1 \\
\hline Sterculiaceae & 1 \\
\hline Arecaceae & 1 \\
\hline Cupressaceae & 1 \\
\hline Meliaceae & 1 \\
\hline
\end{tabular}

Fonte: UNESP, Jaboticabal, SP, 2010 
De acordo com os dados do levantamento verifica-se que praça possui muitas árvores e palmeiras, a maioria delas de grande porte, proporcionando sombra e bem estar àqueles que freqüentam o local.

Dourado e Silva (2005) estudaram as 14 praças da Estância Turística Ilha Solteira, e verificaram a Praça das Crianças como a mais arborizada da cidade, com um total de 92 árvores em uma área de $3.082 \mathrm{~m}^{2}$. Os autores ressaltam que a maioria dos indivíduos são palmeiras da mesma espécie, conferindo ao local um aspecto uniforme, monótono e sem sombreamento.

Ao analisar a vegetação da Praça Ernesto Tochetto, Melo e Romanini (2008) considera o local de grande diversidade de arbóreas, contendo 15 espécies num total de 52 exemplares.

Em alguns canteiros da Praça Sete de Setembro verificam-se grandes áreas descobertas necessitando de renovação na forração, em contrapartida nota-se em outras áreas a falta de poda desta mesma forração, servindo de esconderijo para lixo como copos de plásticos e garrafas de vidro. É aconselhável utilizar uma espécie de forração mais rasteira para evitar tais problemas.

\section{Levantamento quali-quantitativo do mobiliário}

O mobiliário encontrado na Praça Sete de Setembro e as características atuais são:

Existem 55 bancos em bom estado de conservação, são confortáveis, a estrutura é de ferro, o encosto e o assento são de madeira e combinam com o traçado orgânico e sinuoso da praça. A distribuição espacial dos bancos situa-se ao longo do caminho pavimentado, tendo como limite as áreas ajardinadas, são encontrados tanto em locais de sombra como ao sol. Em alguns pontos da praça verifica-se um grande vazio do mobiliário em questão, alguns freqüentadores relataram que este vazio é devido ao vandalismo e que não foram repostos. A quantidade de bancos existentes é relatada pelos usuários como suficientes.

Para Demattê (1999) os bancos devem ser confortáveis, duráveis, de fácil limpeza e aparência discreta. É interessante localizá-los de diferentes modos: ao sol e na sombra; isolados ou em grupos; voltados para dentro e para fora do espaço público. 
O entorno da praça é iluminado com 18 postes de alta tensão e a parte central e os caminhos por 58 postes. Avaliou-se que a infra-estrutura presente, proporciona uma iluminação adequada e que valoriza o projeto paisagístico.

A iluminação tem a função de proporcionar segurança a seus usuários e de manter o valor visual e o conforto do ambiente noturno em níveis semelhantes aos proporcionados pela luz do sol. A distribuição das luminárias deve ser feita de modo a proporcionar aparência homogênea a toda massa de vegetação (DEMATTÊ, 1999).

Há 65 lixeiras de latão espalhadas pelo local, embora a quantidade de lixeiras seja alta não é o suficiente, pois seu volume é de apenas $0.024 \mathrm{~m}^{3}$, transbordando com freqüência os resíduos. As lixeiras eqüidistam em torno de $17 \mathrm{~m}$ uma das outras. Alguns usuários queixaram-se dos locais em que as mesmas foram instaladas, a maioria delas estão ao lado dos bancos, causando desconforto devido ao odor de lixo.

Demattê (1999) relatou que as lixeiras devem ter aparência discreta e agradável, estando espalhadas a distâncias não maiores que $100 \mathrm{~m}$ umas das outras.

Lixeiras grandes, coloridas ou com propagandas caracterizam poluição visual no local (PAIVA, 2001).

Existem 11 telefones públicos no local, nove deles estão protegidos por um quiosque que está localizado próximo à Rua Floriano Peixoto, dois se encontram na esquina da Rua Sete de Setembro com a Rua Lafaiete. Todos estão em bom estado de conservação e funcionamento. Para Paiva (2001), esta estrutura oferece conforto ao usuário.

O piso é pavimentado com cimento e pintado de coloração avermelhada. Encontrase em bom estado de conservação, permitindo aos freqüentadores caminharem com segurança e tranqüilidade.

Para Abbud (2006), o cimentado é um material de baixo custo sendo indicado para pisos, e que pode ser colorido e receber texturas variadas.

O traçado da praça é orgânico e sinuoso e obedece a sua funcionalidade e segurança, permitindo o acesso a todos os pontos da praça.

Para Demattê (1999), os caminhos levemente ondulados propiciam integração maior com os valores paisagísticos, pois dão a impressão de naturalidade e visualmente são mais agradáveis.

Os caminhos de longas distâncias em um único sentido, não estimulam a caminhada, ao contrário, caminhos muito recortados com excesso de curvas ou ângulos cansam, estimulando as pessoas a "cortarem caminho" nos canteiros ou gramados. É 
importante a criação de áreas para o descanso ao longo dos caminhos, espaços mais largos com bancos, bebedouros e sombra (PAIVA, 2001).

O coreto juntamente com o palco feito de alvenaria forma um espaço amplo e bonito e está localizado no centro da praça.

Existe uma única escultura no local, que é notada por poucos, por ser bastante discreta. Ela é feita de madeira e está em bom estado de conservação. Na escultura tem a seguinte gravura: "Que a paz prevaleça no mundo". Esta frase foi gravada em quatro idiomas diferentes (português, inglês, japonês e francês).

$\mathrm{Na}$ praça pode-se verificar a presença de um pergolado feito de alvenaria. Para Paiva (2001), esta estrutura tem a função de propiciar um local de estética bastante atrativa e o caminhamento em área de ligeiro sombreamento.

Não há estacionamento projetado para o local, os carros são estacionados no entorno do quarteirão, sem que haja um recuo da rua para promover segurança aos usuários.

Existe um ponto de táxi na praça, localizado na Rua Florêncio de Abreu em que se verifica a presença de abrigo para os taxistas. Não há ponto para ônibus na praça.

Há uma banca bastante tradicional, que atende as necessidades dos usuários.

Embora não combine com o estilo da praça, há uma lanchonete em um "trailer" que fica localizado na esquina das ruas Floriano Peixoto com Florêncio de Abreu. Nota-se que o proprietário do comércio em questão mantém o local limpo e conservado.

O espaço conta com uma vasta arborização, são árvores que promovem uma beleza natural excelente para o local. Quanto ao paisagismo, verifica-se que as forrações nunca são renovadas, além de pessoas despreparadas plantarem por conta própria, o que poderá futuramente causar conflitos com as espécies já implantadas no local. O local por ser muito arborizado, promove grande conforto térmico e acústico.

A presença da vegetação tem uma função ecológica muito importante como a não impermeabilização do solo, uma fauna mais diversificada em áreas vegetadas, melhorias no clima da cidade e na qualidade do ar, água e solo (GUZZO, 1991).

Embora haja pessoas capacitadas que realizam a limpeza e a conservação da praça diariamente, verifica-se muito lixo descartado pelos usuários em locais impróprios.

A segurança do local é relatada por alguns freqüentadores como ineficiente, o que causa medo e desconforto para utilizar o espaço com tranqüilidade.

Embora este item não esteja na lista de De Angelis et al. (2004), é de extrema importância levá-lo em consideração, para promover a inclusão social das pessoas com

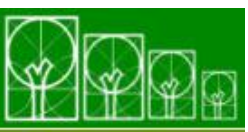

$\mathbf{S} \cdot \mathbf{B} \cdot \mathbf{A} \cdot \mathbf{U}$ Soc. Bras. de Arborização Urbana 
necessidades especiais. A praça possui 10 rampas espalhadas ao seu redor, as mesmas estão em bom estado de conservação e há um respeito muito grande pelos freqüentadores da praça em não impedir a passagem nestas rampas.

Durante o levantamento do mobiliário observou-se, a falta de sanitários, bebedouros, espelho d'água, quadra esportiva, equipamentos para exercícios físicos e parque infantil.

Na tabela 3 estão os resultados da avaliação do mobiliário encontrado na Praça Sete de Setembro.

Tabela 3. Presença e nota do mobiliário encontrado na Praça Sete de Setembro, Ribeirão Preto, SP, 2010

Table 3. Presence and grade of furniture in Sete de Setembro Square, Ribeirão Preto, SP, 2010

\begin{tabular}{|l|c|c|}
\hline \multicolumn{1}{|c|}{ ESTRUTURAS AVALIADAS } & NOTA & AUSÊNCIA \\
\hline 01. Bancos & 3,0 & \\
02. Iluminação alta & 4,0 & \\
03. lluminação baixa & 4,0 & \\
04. Lixeiras & 1,0 & $\mathrm{X}$ \\
05. Sanitários & 4,0 & \\
06. Telefone público & & $\mathrm{X}$ \\
07. Bebedouros & 4,0 & \\
08. Piso & 4,0 & \\
09. Traçado dos caminhos & 3,5 & \\
10. Palco/coreto & 2,5 & $\mathrm{X}$ \\
11. Pergolado & & $\mathrm{X}$ \\
12. Monumento & & $\mathrm{X}$ \\
13. Espelho d'água/chafariz & & \\
14. Estacionamento & \\
15. Ponto de ônibus & 4,0 & $\mathrm{X}$ \\
16. Ponto de táxi & & $\mathrm{X}$ \\
17. Quadra esportiva & & $\mathrm{X}$ \\
18. Equipamentos para exercícios físicos & & \\
19. Estrutura para terceira idade & & \\
20. Parque infantil & 4,0 & \\
21. Banca de revista & 3,0 & \\
22. Quiosque para alimentação e/ou similar & 4,0 & \\
23. Vegetação & 2,5 & \\
24. Paisagismo & 4,0 & \\
25. Localização & 2,5 & \\
26. Conservação/Limpeza & 1,0 & \\
27. Segurança & & \\
28. Conforto ambiental & & \\
\hline
\end{tabular}

Fonte: adaptado de De Angelis et al., 2004 


\section{Pesquisa de opinião}

A opinião dos usuários mostrou a satisfação ou insatisfação dos mesmos para com a praça, revelando problemas ocultos, que só quem freqüenta o local pode relatar.

Os usuários do sexo feminino representaram $61 \%$ do público total que freqüenta o local (figura 1), isso se deve porque próximo à praça há muitos prédios, onde mulheres trabalham como empregadas domésticas, babás ou damas de companhia de idosos que por ali moram. Na maioria dos casos, estas mulheres vão à praça descansar, levar crianças para brincar e passear com os idosos.

Figura 1. Freqüência de usuários segundo o sexo na Praça Sete de Setembro, Município de Ribeirão Preto, SP, 2010

Figure 1. Users frequency by gender in Sete de Setembro Square, Ribeirão Preto, SP, 2010.

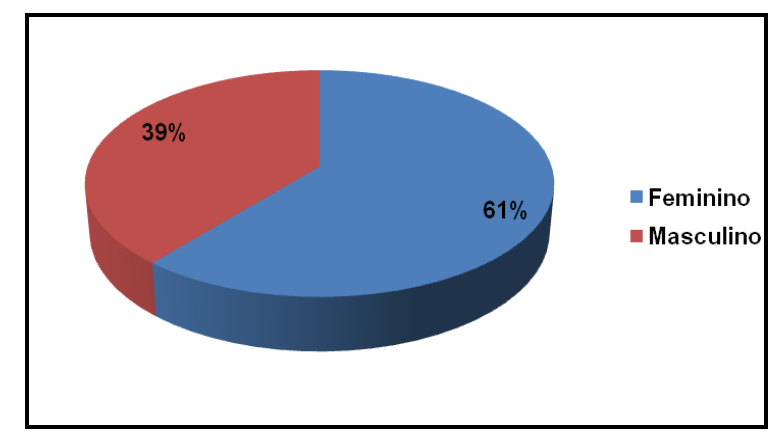

Já Borella (2009) verificou que a Praça D. Assis, Jaboticabal, SP, era freqüentada, em sua maioria (75\%) por usuários masculinos sendo que este alto índice é porque esta praça privilegia o lazer para a terceira idade, sobretudo, jogos de carteado, bem como, aluguel de fretes, atividades mais comuns para o sexo masculino.

Esta diversidade mostra que as praças devem ser tratadas de forma individual, respeitando as características dos usuários e não como foi feito nas décadas de 50 e 60 onde, por iniciativa dos governos municipais, estaduais e federal, desenvolveu-se um programa de criação de praças para todas as cidades brasileiras, as quais foram criadas a partir de um projeto padrão (PIVETTA et al., 2008).

De acordo com a pesquisa de opinião verificou-se que $42 \%$ dos freqüentadores da praça possuem idade entre 21 a 40 anos (figura 2), sendo que $47 \%$ utilizam a praça para descanso, outros utilizam para passear com as crianças e/ou cachorros, encontrar amigos ou mesmo só de passagem.

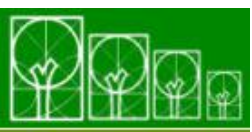

S $\cdot \mathbf{B} \cdot \mathbf{A} \cdot \mathbf{U}$ Soc. Bras. de Arborização Urbana 
Figura 2. Freqüência de usuários segundo a faixa etária na Praça Sete de Setembro, Município de Ribeirão Preto, SP, 2010

Figure 2. Users frequency by age in Sete de Setembro Square, Ribeirão Preto, SP, 2010

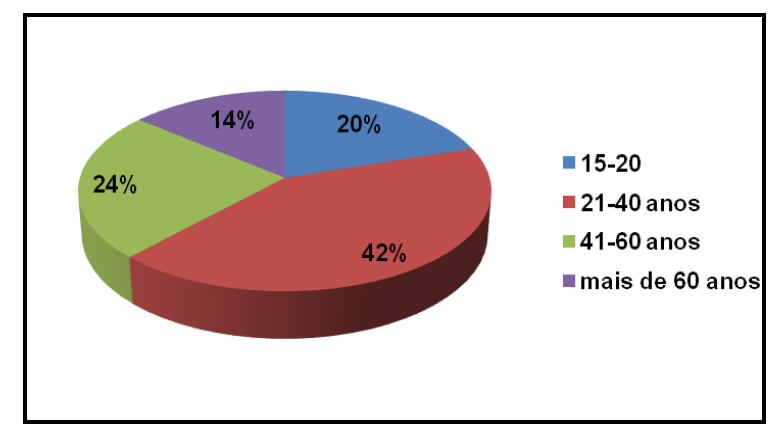

O público idoso da praça é de apenas $14 \%$, eles reclamam que a freqüência de andarilhos e usuários de drogas tem aumentado nos últimos anos, reduzindo o número de idas deste grupo de pessoas à praça.

De forma semelhante e também para praças situadas no centro da cidade, Silva et al. (2007) observaram maior freqüência de jovens e mínimas de idosos nas praças do Bairro Centro de Teresina - PI. Já Silva et al. (2008) relataram que as porcentagens de jovens e idosos foram iguais, e maiores do que jovens adultos (20 - 40 anos), nas Praças Dr. Augusto Silva e Leonardo Venerando Pereira, Lavras, MG. Borella (2009) observou que a grande maioria (69\%) dos freqüentadores da Praça Dom Assis, Jaboticabal, SP, tem mais de 60 anos, seguidos pela faixa etária de 41 a 60 anos (25\%); a presença de jovens foi muito inferior, contando com apenas $6 \%$ sendo, portanto, uma praça com função de lazer para terceira idade.

Mello e Romanini (2008) na Praça Ernesto Tochetto em Passo Fundo, RS, observaram a freqüência dos usuários bastante igualitária para as diferentes faixas etárias, $38 \%$ dos freqüentadores tinham de 15 a 30 anos, 32\% de 31 a 45 anos e 30\% possuíam em torno de 46 a 70 anos de idade.

A escolaridade dos usuários entrevistados foi de $40 \%$ para o ensino médio, $24 \%$ para o nível superior e $13 \%$ para o nível fundamental (figura 3 ). 
Figura 3. Freqüência de usuários segundo a escolaridade na Praça Sete de Setembro, Município de Ribeirão Preto, SP, 2010

Figure 3. Users frequency by educational level in Sete de Setembro Square, Ribeirão Preto, SP, 2010

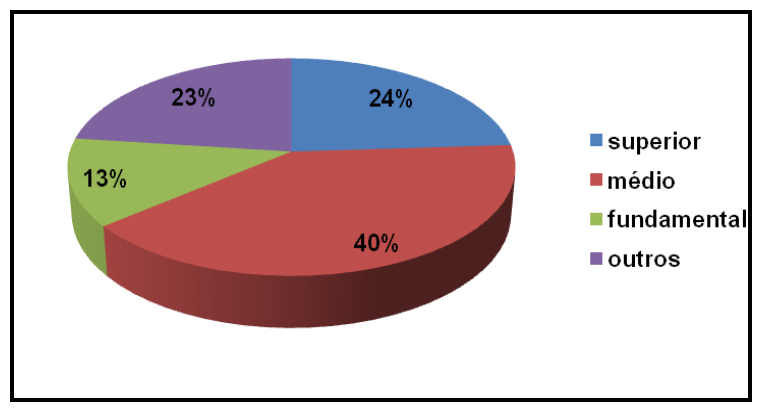

Já Silva et al. (2008) analisando as Praças Dr. Augusto Silva e Leonardo Venerando Pereira, município de Lavras, MG, observaram que a maioria (46\%) dos usuários destas praças apresentavam nível de escolaridade de ensino fundamental, seguido pelo ensino médio (33\%) e superior (21\%)

A maior porcentagem de pessoas com nível de escolaridade entre médio e superior observada neste estudo, pode ser explicada pelo fato da Praça Sete de Setembro estar situada em um município onde há muitas escolas, cursos técnicos e faculdades; deve-se, também, considerar que a grande maioria dos freqüentadores são jovens, aumentando assim esse nível de escolaridade; possivelmente, se a praça fosse mais freqüentada pela população idosa, o nível de escolaridade poderia ser mais baixo.

Com relação à atividade ocupacional dos entrevistados (figura 4), 63\% são trabalhadores, $12 \%$ são estudantes, $12 \%$ são aposentados, $6 \%$ são donas de casa e 7\% estão desempregados. Provavelmente, a maioria dos usuários são trabalhadores porque grande parte está na idade ativa de trabalho (20 a 41 anos) ou, ainda, porque a praça está localizada na região central de Ribeirão Preto, sendo um local de intenso comércio. 
Figura 4. Freqüência de usuários segundo a atividade ocupacional na Praça Sete de Setembro, Município de Ribeirão Preto, SP, 2010

Figure 4. Users frequency by work activity in Sete de Setembro Square, Ribeirão Preto, SP, 2010

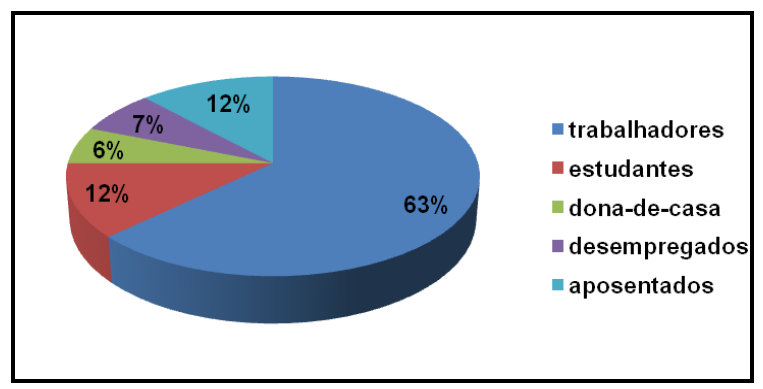

De todos os entrevistados, $85 \%$ dizem ser freqüentadores da praça, alguns vão à praça todos os dias, outros uma vez na semana e outros uma vez ao mês.

Quanto à utilização da praça, verificou-se que $24 \%$ dos usuários utilizam a praça para descansar e 15\% para levar criança para passear (figura 5). Neste quesito de utilização do espaço, diversas respostas foram dadas, como caminhar, levar o cachorro para passear, passar o horário de almoço na praça, utilização da praça apenas como passagem, tomar sorvete (em frente à praça há uma sorveteria bastante tradicional da cidade, atraindo muitas pessoas), namorar, encontrar amigos, etc.

Figura 5. Motivo de utilização da Praça Sete de Setembro, Município de Ribeirão Preto, SP, 2010

Figura 5. Reason for use in Sete de Setembro Square, Ribeirão Preto, SP

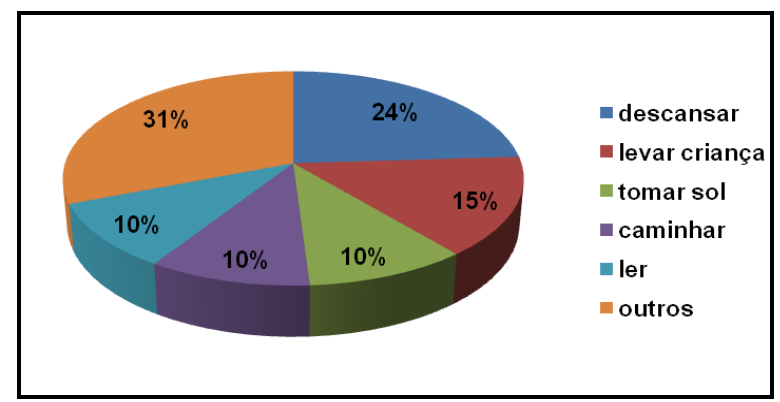

O estudo dos espaços livres e de uso público realizado na cidade de Ribeirão Preto por Guzzo (1999) relatou que a Praça Sete de Setembro foi utilizada para passeio com crianças e cachorros, skate, patins, bicicleta, caminhada, namoro, descanso e contemplação, conversas e etc.

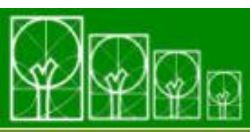


A maioria dos usuários (24\%) permanece por volta de 1 hora na praça. Existem usuários que freqüentam a praça por 15, 30 e 40 minutos e outros 2, 3 a 4 horas por visita.

Quando perguntado aos entrevistados o que eles mais gostam da praça (figura 6), $33 \%$ responderam que gostam das árvores, $19 \%$ da tranqüilidade do local e os demais responderam que gostam do verde, do ar puro, da limpeza e da sombra.

Figura 6. O que mais gostam na Praça Sete de Setembro, Município de Ribeirão Preto, SP, 2010

Figura 6. Favorite features in Sete de Setembro Square, Ribeirão Preto, SP, 2010

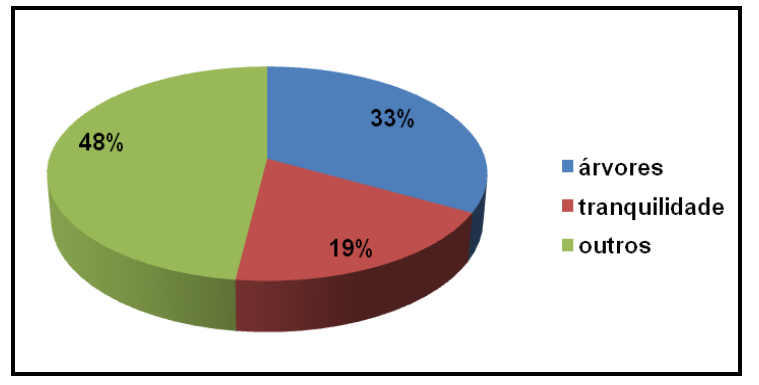

Guzzo (1999) verificou em seu estudo espaços livres que os usuários são atraídos pela tranqüilidade e beleza, pelas árvores, segurança, o canto dos pássaros, limpeza e etc.

Quanto ao que menos gostam na praça, 44\% dos entrevistados não gostam da presença de mendigos, usuários de drogas e os "guardadores de carro".

Cerca de $10 \%$ dos entrevistados preferiram não opinar e, $17 \%$ não têm nada a reclamar da Praça Sete de Setembro.

Às quartas-feiras durante a pesquisa de opinião, verificou-se a ocorrência de encontros de casais homossexuais, causando certo receio aos demais usuários que freqüentam a praça, pois segundo os próprios entrevistados, se sentem desconfortáveis com as atitudes expostas por esse grupo de pessoas.

Quando os usuários foram questionados sobre o que é necessário melhorar na praça, 37\% responderam a segurança, sugerindo mais policiamento e solicitando guarda municipal 24 horas na praça, 15\% estão satisfeitos e a praça não precisa de melhorias, e os demais sugeriram melhoria na limpeza, instalação de bebedouros e torneiras para higiene das mãos, construção de banheiro, parquinho para as crianças, entre outros.

Destacaram-se como maior problema relatado pelos entrevistados, a presença de andarilhos, usuários de drogas e pessoas que ficam pedindo esmolas em troca de cuidar dos carros estacionados ao redor da praça, estes são vistos como ameaça à segurança da

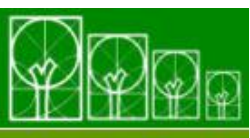

$\mathbf{S} \cdot \mathbf{B} \cdot \mathbf{A} \cdot \mathbf{U}$ Soc. Bras. de Arborização Urbana 
população que freqüenta o local. O pedido de segurança foi unânime pelos usuários. Embora seja feita a ronda pela Polícia Militar e Guarda Municipal, os mesmos não permanecem no local por muito tempo, o que traz desconforto a população local, no entanto não houve relatos de casos de ocorrência policial por nenhum usuário.

Quando questionados sobre as outras praças de Ribeirão Preto, alguns responderam que as consideram abandonadas tanto na parte de cuidados e manutenção (35\%), como na segurança (25\%), já outros consideram as praças "boas" (19\%) e 13\% não opinaram, 8\% dos entrevistados não deram respostas significativas. Algumas pessoas não quiseram opinar, pois freqüentam apenas a Praça Sete de Setembro.

A maioria dos entrevistados (62\%) concordou que a mudança na infra-estrutura da praça ao longo dos anos trouxe melhorias para o local, ressaltando a limpeza e o policiamento. Em contrapartida, $7 \%$ disseram que a praça piorou em relação ao público que a freqüenta e a falta de limpeza. Parte significativa da entrevista (31\%) relatou não ter notado melhoria ou piora na praça (figura 7).

Figura 7. Mudanças na infraestrutura da Praça Sete de Setembro ao longo dos anos, Município de Ribeirão Preto, SP, 2010

Figure 7. Changes infrastructure over the years in Sete de Setembro Square, Ribeirão Preto, SP, 2010

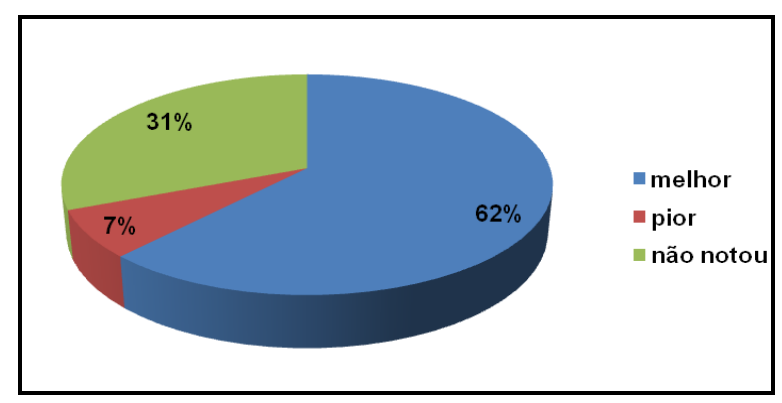

Quanto ao quesito limpeza na praça, há uma controvérsia, isso ocorre devido ao horário de freqüência do usuário no local. No período da manhã, a praça é varrida e as lixeiras são esvaziadas, a limpeza permanece até por volta das 14 horas. Após esse horário, verificou-se a péssima utilização do bem público pelos próprios usuários, que descartam papéis, copos, embalagens e outros objetos de forma indevida.

Dentre os entrevistados, $74 \%$ souberam o nome atual da praça (figura 8 ), ou seja, Sete de Setembro, visto que no passado chamava-se "Aureliano de Gusmão", o que 
provocou confusão aos entrevistados; algumas pessoas ainda acreditavam que o nome da praça permanecia o antigo.

Figura 8. Conhecimento das pessoas sobre o nome da Praça Sete de Setembro, Ribeirão Preto, SP, 2010

Figure 8. People knowledge about square name, City of Ribeirão Preto, SP, 2010

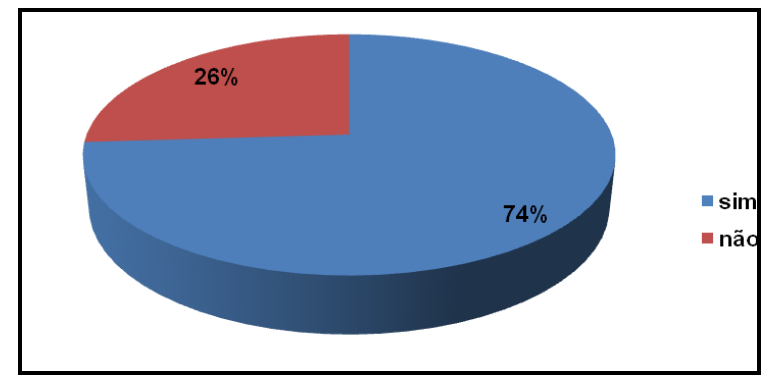

Melo e Romanini (2008), analisando a Praça Ernesto Tochetto, Passo Fundo, RS, observaram índices semelhantes de conhecimento do nome da praça, sendo da ordem de 23\% para os usuários cuja faixa etária era de 46 a 70 anos, 35\% para 31 a 45 anos e somente entre os mais jovens (15 a 30 anos) verificaram-se grande porcentagem (42\%) de usuários que não sabiam o nome da praça.

Ao perguntar para as pessoas sobre a história da Praça Sete de Setembro, apenas $3 \%$ relataram ter ouvido que antes havia um cemitério instalado no local.

Semelhantemente, Borella (2009) verificou que a maioria (83\%) dos usuários tinha conhecimento do nome da praça (D. Assis, Jaboticabal, SP), porém, somente $3 \%$ sabiam sobre a história da mesma. No entanto, a maioria dos usuários tinha mais que 60 anos, sendo mais comum conhecer aspectos ligados à história do município.

\section{CONCLUSÕES}

Concluiu-se que a Praça Sete de Setembro apresenta a função de reunir e promover lazer a diferentes grupos de pessoas, preferencialmente do sexo feminino, de 21 a 40 anos, que a usam para descanso e passeio com as crianças; oferece aos seus usuários um mobiliário adequado e em bom estado de conservação; apresenta grande diversidade de espécies arbóreas (85 espécies em 280 exemplares). 


\section{REFERÊNCIAS BIBLIOGRÁFICAS}

ABBUD, B. Criando paisagens - Guia de trabalho em arquitetura. 3.ed. São Paulo: SENAC, 2006. p. 1-6.

APG II. 2003. An update of the Angiosperm Phylogeny Group classification for the orders and families of flowering plants: APG II. Botanical Journal of the Linnean Society 141:399-436.

BORELLA, H. D. Importância histórica - cultural e situação atual da Praça Dom Assis, Jaboticabal, São Paulo. 2009. 50p. (Trabalho de Conclusão de Curso) - Faculdade de Ciências Agrárias e Veterinárias - Universidade Estadual Paulista FCAV/Unesp, Jaboticabal, SP.

BRUMMITT, R. K.; POWELL, C. E. Authors of plant names: A list of authors of scientific names of plants, with recommended standard forms of their names, including abbreviations. Richmond, Surrey: Royal Botanic Gardens Kew. 1992. 732 p.

DE ANGELIS, B. L. D.; ANGELIS NETO, G. de. Os elementos de desenho das praças de Maringá-PR. Acta Scientiarum, Maringá, v. 22, n. 5, p. 1445-1454, 2000.

DE ANGELIS, B. L. D.; CASTRO, R. M.; DE ANGELIS NETO, G. Metodologia para levantamento, cadastramento, diagnóstico e avaliação de praças no Brasil. Engenharia civil, n.20, p.57-70, 2004.

DE ANGELIS, B. L. D.; DE ANGELIS NETO, G.; MOTA, C. R.; SCAPIN, C. R.; MANO, L. R.; SCHIAVON, V. S.; HOFFMANN, A. C.; SAVI, E.; SILVA, G. F. F.; RECCO, L. H.; BARCOS, M.; SANTANA, M.; FANTINI, P. R.; DOMINGUES, R.; BARBEIRO, T. L.; YUASSA, V. N. Avaliação das praças de Maringá, Estado do Paraná, Brasil. Acta Scientiarum, Maringá, v.27, n.4, p.629-638, 2005.

DEMATTÊ, M. E. S. P. Princípios de paisagismo. 2. ed. Jaboticabal: FUNEP, 1999, p. 101. 
DOURADO, L. A. C.; SILVA, E. A. Espacialização e ordenamento das praças, espaços de recreação e lazer, na Estância Turística Ilha Solteira - S.P. Revista Eletrônica da Associação dos Geógrafos Brasileiros - Seção Três Lagoas. Três Lagoas - Mato Grosso do Sul, v. 2, n. 2, 2005.

GUZZO, P. Estudos dos espaços livres de uso público da cidade de Ribeirão Preto/SP, com detalhamento da cobertura vegetal e áreas verdes públicas de dois setores urbanos. 1999. 126f. Dissertação (Mestrado em Geografia) - Instituto de Geociências e Ciências Exatas, Universidade Estadual Paulista, Rio Claro, 1999.

GUZZO, P. Arborização urbana. 1991. Disponível em:

<http://educar.sc.usp.br/biologia/prociencias/areasverdes.html>. Acesso em: 13 out. 2009.

IBGE - INSTITUTO BRASILEIRO DE GEOGRAFIA E ESTATíSTICA. Disponível em: <http://www.ibge.gov.br/cidadesat/topwindow.htm>. Acesso em: 09 fev. 2010.

LORENZI, H. Árvores brasileiras: Manual de identificação e cultivo de plantas arbóreas nativas do Brasil. Nova Odessa/SP: Plantarum, 1992, 368p.

MELO, E. F. R. Q.; ROMANINI, A. Praça Ernesto Tochetto: importância da sua preservação histórica e aspectos de sua arborização. Revista da Sociedade Brasileira de Arborização Urbana, Piracicaba, v.3, n.1, p.54-52, 2008.

PAIVA, P. D. de O. Paisagismo II: Macro e micropaisagismo. Lavras: UFLA/ FAEPE, 2001. $112 \mathrm{p}$.

PEGOLO, L. C. N. C.; DEMATTÊ, M. E. S. P. Estudo sobre as principais praças de Jaboticabal e Taquaritinga, SP. Holos Environment, v.2, n.1, p.106-123, 2002.

PIVETTA, K. F. L.; PAIVA, P. D. O.; NERI, F. C. S. Paisagismo em grandes espaços. In: PAIVA, P. D. O. Paisagismo: conceitos e aplicações. Lavras: UFLA, 2008. p.179-211.

SILVA, I. M.; RAMOS, L. M. P.; BRITO, J. S. Análise das funções das praças do bairro centro de Teresina - PI. In: CONGRESSO DE PESQUISA E INOVAÇÃO DA REDE NORTE 
NORDESte DE EDUCAÇÃo TECNOLÓGICA, 2, 2007, João Pessoa. Anais... João Pessoa, 2007.

SILVA, A.T.; TAVARES, T.S.; PAIVA, P.D.O.; NOGUEIRA, D.A. As Praças Dr. Augusto Silva e Leonardo Venerando Pereira, Lavras-MG, segundo a visão dos seus freqüentadores. Ciência e Agrotecnologia, v. 32, n. 6, p. 1701-1707, 2008.

SOUZA, B. A. de A. Análise da utilização pelos usuários de duas praças em Betim-MG. (Monografia) - Universidade Federal de Lavras, Lavras, MG, 2005. 53p.

SOUZA, V. C.; LORENZI, H. Botânica sistemática: guia ilustrado para identificação das famílias de angiospermas da flora brasileira, baseado em APG II. Nova Odessa/SP: Instituto Plantarum de Estudos da Flora Ltda, 2008, 704p. 